\title{
O ANTITERRORISMO APÓS o 11/09 COMO LEGITIMAÇÃO DO NOVO POLICIAMENTO GLOBAL
}

\author{
Geraldo Alves Teixeira Júnior ${ }^{1}$
}

\begin{abstract}
Resumo
0 artigo aborda o significado da expressão "polícia do mundo", recorrente entre os críticos do imperialismo americano. A partir da década de 1970, o termo adquire outros significados, pois os Estados Unidos passam a empregar novos procedimentos para exercer seu poder de polícia global no contexto da "guerra contra as drogas". Desde os atentados de 11 de setembro de 2001, o novo policiamento internacional se tornou mais freqüente e mais agressivo com as chamadas extraordinary renditions na "guerra contra o terror". De modo geral, busca-se mostrar que o problema do policiamento internacional vai além das análises sistêmicas. Como objetivo específico, pretendese realçar que as práticas aí envolvidas e outrora rejeitadas adquirem legitimidade quando são justificadas pelo discurso do combate ao terrorismo internacional.
\end{abstract}

Palavras-chave: Estados Unidos. Política externa. Antiterrorismo. Policiamento global.

\section{ANTI-TERRORISM POLICIES AFTER SEPTEMBER 11 AS MEANS OF LEGITIMATING THE NEW WORLD POLICING}

\begin{abstract}
This article discusses the meaning of the expression "world police", constantly used by the critics of American imperialism. As from the 1970's the expression acquires other meanings, as the United States starts to employ new procedures to exercise its police powers in the context of the global "war on drugs." Since the September 112001 attacks, the new international policing became more frequent and more aggressive, with the so-called extraordinary renditions of the "war on terror." The overall purpose of this text is to show that the problem of international policing goes beyond systemic
\end{abstract}

${ }^{1}$ Doutor em Filosofia pela Universidade Estadual de Campinas, Brasil. gatjr@uol.com.br 
analysis. It is also emphasized that, although the practices analyzed have been largely rejected in the past, they are now often seen as legitimate when justified by the discourse of combating international terrorism.

Keywords: United States. Foreign policy. Antiterrorism. World policing.

\begin{abstract}
O POLICIAMENTO GLOBAL
bem conhecida a crítica à pretensão dos Estados Unidos (EUA) de agirem como uma "polícia do mundo". 0 significado desta crítica era inequívoco até muito recentemente, mas é possível compreender que no contexto do combate ao terrorismo ela adquire um significado ainda mais grave do que aquele que ela guardava em seu uso tradicional.
\end{abstract}

Ao que parece, a expressão mencionada, ao contrário da conotação crítica que possui atualmente, tem origem oficial. É um legado do "Corolário Roosevelt":

Theodore Roosevelt conferiu à Doutrina Monroe o seu significado mais intervencionista ao identificá-la com as doutrinas imperialistas do período. Por meio daquilo que chamou de um "Corolário" à Doutrina Monroe, ele proclamou em 06 de dezembro de 1904 um direito geral de intervenção por "alguma nação civilizada", o qual, no hemisfério ocidental, apenas os Estados Unidos tinham o direito de exercer: "... No hemisfério ocidental, a adesão dos Estados Unidos à Doutrina Monroe pode forçar os Estados Unidos, embora relutantes, a exercer em casos flagrantes de infração (wrong-doing) ou impotência, um poder de polícia internacional." (KISSINGER, 1994, p. 39 , grifo nosso $)^{2}$

Em termos gerais e em seu emprego mais comum, a expressão "polícia do mundo" é utilizada para tratar de intervenções militares ou de políticas secretas levadas a cabo pelo Estado norte-americano contra grupos que assumem o poder em um determinado país, e que contrariam os interesses norte-americanos. 0 dito policiamento, contudo, não é simplesmente reativo, isto é, ele não espera que uma situação se consolide antes de agir. A expressão citada indica ainda as práticas utilizadas para conduzir ao governo grupos que correspondem às suas expectativas e impedir que os grupos contrários o façam. Inúmeros são os exemplos dessas práticas, bem conhecidas especialmente pelos países do continente americano, mas dispersa, em distintos momentos, por todo o globo (AJCHENBAUM, 2003).

\footnotetext{
${ }^{2}$ A citação feita por Kissinger é trecho de um pronunciamento de Roosevelt ao Congresso. Todas as traduções do inglês são de nossa responsabilidade.
}

O ANTITERRORISMO APÓS O 11/09...

G. A.TeiXeira Júnior • 141 
Um dos casos pioneiros desse policiamento internacional - antes mesmo da declaração do Corolário Roosevelt - foi o que envolveu a construção do Canal do Panamá no fim do século XIX e início do XX. Na ocasião, os EUA exerceram papel importante para que o Panamá se separasse do governo da Colômbia e formasse um Estado independente. Após ter sua proposta de acordo para a construção do canal negada pelo Congresso colombiano, o governo americano apoiou os independentistas da província do Panamá. A região independente, tornada um novo Estado, aceitou os termos do tratado proposto pelos EUA, o que possibilitaria que este construísse e administrasse o canal por longo tempo. Vale sublinhar que, como também seria em muitos outros casos, o apoio não foi uma mera declaração, mas envolveu deslocamento de efetivos militares (DOREL, 2006, p. 13). 0 controle dos EUA sobre o canal ocorreu até 1999 e foi de relevância maior para a política e para a economia americanas.

Durante a Guerra Fria, era ainda mais claro que os Estados Unidos criavam "leis" que deveriam ser seguidas pelos Estados de sua esfera de influência que não quisessem sofrer intervenções. Se a disciplina não viesse pelo convencimento chegaria pela força. E assim foi. No discurso legitimador de tais políticas, tratavase de proteger o "mundo livre" contra a "ameaça vermelha". Em Cuba, esse "policiamento" dos EUA ocorreu de modo menos discreto até a revolução de 1959. E certamente teria continuado caso as tentativas de assassinar Fidel Castro tivessem sido bem sucedidas ${ }^{3}$.

Interessa ressaltar que tais práticas já não eram desenvolvidas casualmente; elas foram institucionalizadas durante a Guerra Fria. Já, no final da década de 1940, surgiu o Office of Policy Coordination (OPC), em consequiência da diretiva do Conselho Nacional de Segurança (National Security Counsil) que definiu que a CIA deveria criar uma seção responsável por

[...] propaganda; guerra econômica, ações diretas preventivas, incluindo sabotagem, medidas de demolição e evacuação; subversão contra estados hostis, incluindo assistência a movimentos secretos, guerrilhas e grupos de liberação de refugiados, e apoio a elementos indígenas $s^{4}$ anticomunistas em

\footnotetext{
${ }^{3}$ McNamara, secretário de Defesa nos governos Kennedy e Johnson, comenta que as várias tentativas de assassinar Fidel Castro tiveram mais influência sobre o desenvolvimento da Crise dos Mísseis do que a invasão da Baía dos Porcos: "[... ] Do ponto de vista de Cuba e da Rússia o mais importante é que eles sabiam de um modo que eu não sabia, que nós havíamos tentado assassinar Castro durante o governo Eisenhower, durante o governo Kennedy e mais tarde durante o governo Johnson." (fala extraída do vídeo The Fog of War, 2003).

${ }^{4} 0$ termo "indigenous" refere-se aqui à população local em geral.
} 
países ameaçados do mundo livre (FEDERATION OF AMERICA SCIENTISTS, 2011) ${ }^{5}$

0 órgão deixou suas marcas no Chile. Quando as pesquisas eleitorais apontaram Salvador Allende como favorito, mas ainda antes de sua posse, Thomas Karamessines, um agente da CIA que havia trabalhado no OPC quando este foi fundado, e que na década de 1970 era "diretor delegado de planejamento da CIA" (CIA deputy director of plans), transmitiu a seguinte mensagem para o chefe da agência em Santiago (CIA station chief in Santiago):

2. É uma política firme e continuada de que Allende deve ser deposto por um golpe. Seria altamente preferível que isso ocorresse antes do dia 24 de outubro [de 1970], mas os esforços nesse sentido continuarão de modo vigoroso além desta data. Nós devemos continuar a gerar pressão máxima com tal propósito, utilizando todos os recursos apropriados. Faz-se imperativo que estas ações sejam implementadas clandestinamente e de modo seguro de tal modo que o governo dos Estados Unidos e a mão americana estejam bem escondidos. ${ }^{6}$

Quando Allende foi eleito em 1970, os Estados Unidos começaram de imediato várias ações políticas e econômicas para desestabilizar o governo. Logo após a eleição de Allende, o Secretário de Estado do governo Nixon, Henry Kissinger, já havia liberado U\$ 10 milhões para esse propósito (KALFON, 2003, p. 40). Apesar do grande prejuízo causado ao governo chileno, a parte "diplomática" do plano não havia funcionado tão bem quanto se esperava, de modo que nas eleições parlamentares de 1973 a coligação de partidos Unidade Popular, apoiadora do governo Allende, havia conseguido mais de 40\% dos votos. 0 restante da história é bem conhecido: bombas, perseguições, ditadura.

Todas essas intervenções, assim como as que ocorreram em outros continentes, possuem em comum o fato de visar o controle de um Estado por meio de uma política que, com algumas exceções, não pretende anexar territorialmente o Estado a ser controlado. A metáfora da "polícia do mundo" é entendida, assim, como uma comparação com a política interna. As ações policiais dos EUA

\footnotetext{
${ }^{5}$ Memorando do National Security Council "NSC 10/2" (18/06/1948) (citado em FEDERATION OF AMERICAN SCIENTISTS, 2011, onde há um resumo editorial de uma publicação do Departamento de Estado sobre documentos das relações exteriores americanas).

${ }^{6} 0$ texto está disponível no site: http://www.namebase.org/foia/ch03.html, que possibilita buscas de documentos publicados pelo National Security Archive (NSA). No site oficial do NSA é possível também a busca de documentos, mas eles são escaneados, o que pode dificultar a pesquisa. Ali, o fac-símile deste documento citado pode ser encontrado em: http://www.gwu.edu/ nsarchiv/ NSAEBB/NSAEBB8/ch05-01.htm.
}

O ANTITERRORISMO APÓS O 11/09... 
seriam aquelas nas quais a grande potência age com os demais Estados assim como os Estados agem com seus súditos: disciplinando e punindo para garantir o cumprimento das regras e, idealmente, a obediência inconsciente. Esta crítica é, principalmente, a crítica ao imperialismo americano. Há uma vasta literatura teórica e informativa a respeito do tema. A proposta, no entanto, não é a de discutir os argumentos que tais textos levantam ou os casos que eles comentam, mas apenas a de recuperar alguns eventos históricos para fins de contextualização e comparação, isto é, para que seja possível sublinhar a diferença de significado que a expressão "polícia do mundo" irá adquirir no final da década de 1990, e, sobretudo, com a doutrina Bush.

\section{Precursores do novo Policiamento}

A partir da década de 1970 a política policial do Estado americano no exterior passa por mudanças ${ }^{7}$ para que pudesse atuar com maior eficácia no contexto da "guerra contra as drogas", declarada pelos Estados Unidos. A nova prática do policiamento internacional é a incursão de agentes americanos em território estrangeiro e a prisão de indivíduos que são, em seguida, levados aos Estados Unidos para serem julgados por desrespeitarem uma lei federal. Neste momento, as agências executoras destas ações são a DEA (Drug Enforcement Agency) e o FBI (Federal Bureau of Investigation). Alguns casos de prisões extraterritoriais ocorridos ainda nos anos 1970 são citados por Zaid (1997, p. 431 nota 14).

No final da década de 1980 o órgão de assessoria jurídica (Office of Legal Counsel) do Departamento de Justiça produz um parecer cujas premissas legais ressoarão nos argumentos que George W. Bush utilizará para defender sua "guerra contra o terror" (FBI, 1989). É inviável apresentar aqui uma análise mais completa do documento, mas, como é possível notar por seu próprio título, o documento sustenta a legalidade das apreensões extraterritoriais realizadas pelos agentes federais americanos. Mais importante ainda é ressaltar que em julgamento de 1992 a Suprema Corte americana sustentou a legalidade de tais práticas, em um caso no qual o país de onde o indivíduo havia sido retirado possuía tratado de extradição com os EUA (United States v. Alvarez-Machain, 1992). Os memorandos do Departamento de Justiça sobre o tema, assim como os argumentos apresentados no julgamento citado e o desfecho do caso são de

\footnotetext{
${ }^{7}$ Vale reforçar que tais "mudanças" devem ser entendida como adição e não como substituição. Não há motivos para se acreditar que as práticas de intervencionismo mais tradicionais, como as acima citadas, tenham sido abandonadas em algum momento.
} 
grande relevância para compreender os antecedentes das práticas policiais que se tornaram mais visíveis a partir do governo Bush (ALVES, 2011) que, no entanto, não poderão ser tratados neste espaço.

Apesar de possuir precursores importantes, a prática de apreensão extraterritorial e o deslocamento de prisioneiros entre diversos países teriam deixado de ser ocasionais e se tornado política constante do Estado em 1995, quando se formou um programa da CIA encarregado de sua realização. A data é apontada tanto por Michael F. Scheuer, ex-membro da CIA que se diz autor do programa (CONGRESSIONAL RESEARCH SERVICE, 2009, p. 5), quanto pela organização Anistia Internacional (AMNESTY INTERNATIONAL, 2006, p. 1). A partir do momento citado, tais práticas serão definidas em função do combate ao terrorismo, o qual ainda não havia se tornado elemento central da política de segurança dos EUA, mas ganhava importância gradual. Como será possível notar abaixo, uma diferença essencial é que o objetivo da captura dos prisioneiros já não é, desde então, o seu julgamento nos Estados Unidos.

\section{O NOVO POLICIAMENTO DO MUNDO E AS EXTRAORDINARY RENDITIONS}

É no contexto das políticas de combate ao terrorismo que a expressão "polícia do mundo" adquire significado pleno, pois as práticas policiais em territórios estrangeiros possuem então um status institucional, passam a dispor de recursos próprios e buscam ser legitimadas no discurso político.

Após os atentados de 11/09, diversas incursões dos agentes dos EUA em outros países visando à prisão de determinadas pessoas foram denunciadas porque ocorreram sem o conhecimento dos governos que possuíam jurisdição sobre o local ou sobre as pessoas. Em casos diplomaticamente menos problemáticos, havia um acordo entre os EUA e o outro país para que as detenções ocorressem. De um modo geral, estas práticas são tratadas sob o termo "extraordinary renditions", e não se resumem à execução de prisões pelos EUA. Em muitos casos os agentes americanos não participam da ação, mas recebem o prisioneiro após este ter sido apreendido pelas autoridades locais e o transportam para outro país. Em outros casos, ainda, a pessoa é capturada nos portos de entrada dos EUA, inclusive aeroportos, e enviados para o exterior como suspeitas de terrorismo, em um procedimento diferente de uma deportação legal. Em seu significado abrangente, a expressão extraordinary renditions envolve, então, o envio de um país ao outro, sem recorrência a qualquer procedimento legal, nacional ou internacional, de uma pessoa feita prisioneira por qualquer dos governos. 
0 governo americano reconheceu publicamente o programa no governo Bush, sustentando que ele tem uma importância vital na "guerra contra o terror" (MARINER, 2008). Segundo os argumentos oficiais, tais práticas não são ilegais já que são respaldadas pela lei americana e atendem aos requisitos impostos por tratados internacionais como a Convenção Contra a Tortura e Outros Tratamentos ou Punições Cruéis, Desumanas ou Degradantes. A veracidade dessas afirmações poderá ser julgada em face de alguns exemplos que serão apresentados abaixo.

A falta de formalidade dos procedimentos citados produziu tantas prisões equivocadas que a própria CIA investiga algumas "erroneous renditions". Há um vocabulário sombrio criado para tratar do assunto: as pessoas que ficam presas ou desaparecem devido a essas práticas são chamadas "ghost prisioners". Os vôos nos quais elas são conduzidas à prisão ou à morte são chamados "ghost flights". E os locais onde os EUA mantêm prisões secretas, espalhadas por diversos países, são conhecidos como "black sites". Na Europa, comissões foram instauradas, tanto pelas instituições da União Européia quanto pelos Estados membros, para investigar a colaboração dos países do bloco com o programa. Já em 2005, Dick Marty, então Relator-presidente do Comitê do Parlamento Europeu sobre o tema, apontava que as informações encontradas tendiam a "reforçar a credibilidade das alegações que dizem respeito às transferências e detenções temporárias de indivíduos nos países europeus, sem qualquer envolvimento judicial" (Dick MARTY apud AMNESTY INTERNATIONAL, 2006, p. 10). A participação de Estados europeus nestes procedimentos se tornou, com o tempo, mais conhecida (AMNESTY INTERNATIONAL, 2011). Em alguns casos, como nos discutidos abaixo, as extraordinary renditions envolvendo governos da Europa vieram a público por meio de processos judiciais que culminaram na emissão de mandados de prisão contra os agentes americanos envolvidos nesses atos.

É difícil saber quando há ou não colaboração entre a CIA e o poder local, pois os governos envolvidos sempre negam qualquer participação. Um caso no qual o governo do cidadão preso não é acusado de participação no procedimento ${ }^{8}$ é o do seqüestro de um alemão de descendência libanesa, realizado pela CIA na fronteira entre a Albânia e a Macedônia. Khaled Al-Masri foi detido em dezembro de 2003 e levado ao Afeganistão. Torturado e interrogado por cinco meses em Kabul, ele foi liberado em uma floresta na Albânia, quando os agentes disseram a ele que ele tinha sido detido por um "erro de identidade". 0 caso resultou em

\footnotetext{
${ }^{8}$ Ao que parece a justiça da Alemanha não acusou formalmente qualquer membro ou agente do governo. Nesse caso, porém, a imprensa alemã sustenta que o governo teria fornecido informações para agentes americanos, a fim de facilitar o seqüestro e as torturas (ESCÂNDALO..., 2005).
} 
processos judiciais em vários países: na Alemanha, na Macedônia, na Albânia e no próprio EUA.

Na Alemanha, em janeiro de 2007, a justiça emitiu um mandado de prisão para 13 agentes da CIA, mas naquele momento os nomes reais desses suspeitos não tinham sido descobertos. Tendo conduzido as investigações às verdadeiras identidades, um novo mandado foi expedido pela corte de Munique e solicitada a extradição. Diante de tais acontecimentos, os órgãos americanos criticavam 0 comportamento do Estado alemão dizendo que a Alemanha emitia mandados de prisão contra os agentes da inteligência dos EUA, mas queriam que as informações conseguidas por eles fossem compartilhadas.

Durante esse processo houve um contato entre o Ministro de Justiça da Alemanha e o Departamento de Justiça dos EUA para lidar com o tema e, segundo Eva Schmierer, a porta-voz do ministro alemão, o órgão americano teria dito que extraditar os americanos iria "prejudicar os interesses nacionais" daquele Estado, a partir do que o governo alemão decidiu não pedir a extradição. Na tentativa de apaziguar as pressões pelo pedido de extradição, Angela Merkel buscou justificar a postura de seu governo afirmando, sem outras explicações, que o governo dos EUA já havia reconhecido o erro. Em junho de 2008, um grupo de advogados alemães de direitos civis entrou com uma ação contra seu governo para tentar forçar o pedido de extradição, mas, ao que parece, fora o contato extra-oficial mencionado, o governo alemão se recusou a tomar ações para a extradição.

Nos Estados Unidos, quem entrou com a ação foi aAmerican Civil Liberties Union (ACLU), no final de 2005, alegando que o tratamento dispensado a AlMasri era contrário tanto à Constituição quanto às leis internacionais. 0 judiciário americano, atendendo ao pedido do governo, rejeitou a ação em primeira instância, alegando privilégios sobre segredo de Estado, o qual não poderia ser revelado sem comprometer a segurança nacional. A Corte de Apelação - tribunal de segunda instância - confirmou essa decisão e o caso foi para a Suprema Corte (El-Masri v. United States, 2007), onde a decisão não foi diferente: resolveu-se pela não-aceitação do processo ${ }^{9}$. Retomando a jurisprudência de um caso de 1953 (United States $v$. Reynolds), o texto final da decisão argumentava: "há um perigo razoável de que assuntos militares que, no interesse da segurança nacional, não

\footnotetext{
${ }^{9}$ ASuprema Corte dos Estados Unidos pode escolher julgar as ações judiciais que lhe são apresentadas (Cf. o site do Judiciário federal americano, na seção: US Supreme Court Procedures. Disponível em: http://www.uscourts.gov/EducationalResources/ConstitutionResources/SeparationOfPowers/ USSupremeCourtProcedures.aspx).
}

O ANTITERRORISMO APÓS O 11/09...

G. A.TeIXeIRA JÚNIOR • 147 
deveriam ser divulgados, sejam expostos ao se obrigar a apresentação das provas" (apud GREENHOUSE, 2007). Diante da resposta da Suprema Corte, a ACLU propôs, então, que as análises fossem feitas pelo Judiciário sem permitir a divulgação dos documentos. 0 que era solicitado, com este recurso, não era o julgamento no mérito, mas apenas que se considerasse se haviam razões concretas - para além do simples argumento genérico sobre interesses nacionais - para que o caso não fosse julgado. Mas a tática tampouco surtiu efeito. As queixas dos advogados da ACLU envolvidos no caso apontavam para a negligência do Judiciário, que não se dispôs nem mesmo a analisar a questão antes de decidir que o caso não seria julgado (GREENHOUSE, 2007).

Em outros casos, a colaboração do governo local com os EUA é mais facilmente perceptível. Um desses casos de cooperação inconfessa parece ser o do seqüestro de Osama Nasr, mais comumente conhecido como Abu Omar, ocorrido em 2003 na Itália. A vítima do seqüestro possuía nacionalidade egípcia e era imã em Milão, onde vivia com o status legal de refugiado político. Abu Omar foi seqüestrado em plena luz do dia quando estava a caminho da mesquita, e levado para a base aérea americana de Aviano, de onde seguiu para a Alemanha. Ali ele foi transferido para outro avião e levado ao Egito. Em Cairo ele foi torturado e exposto a maus tratos, até que em abril de 2004 ele foi liberado sob a condição de que permanecesse em silêncio. Logo após sua soltura, no entanto, ele telefonou para sua família em Milão, que até aquele momento ainda não havia recebido informações sobre o que the havia ocorrido. Ao fim do telefonema ele foi novamente capturado pelos egípcios e levado de volta para a prisão - o que indica que a ligação estava sendo interceptada. No total, ele ficou preso durante quatro anos - até fevereiro de 2007 - sem acusação e sem julgamento, até que uma corte egípcia decidiu que sua detenção era "infundada".0 governo italiano nega envolvimento no caso. No entanto, há vários indícios da participação de agentes do serviço secreto italiano, o SISMI. Cinco agentes italianos foram acusados pela justiça de Milão de terem tomado parte no seqüestro, dentre eles Nicolò Pollari, chefe militar do serviço secreto, demitido logo que Romano Prodi se tornou Primeiro-Ministro em 2006. Descobriu-se, por meio de escutas telefônicas, que Pollari estava tramando contra os juízes de Milão envolvidos no caso, além de buscar meios de afastar as investigações de Milão e conduzi-las a Brescia, onde fica a base americana citada, e onde a investigação poderia ser controlada. Outras tentativas de enganar as investigações, ou "depistaggi", já haviam sido realizadas pela CIA e pelos italianos, por meio da produção de falsas pistas e evidências. Além 
dessas indicações da participação do governo da Itália, outro fator que aponta no mesmo sentido é a indisposição do Executivo italiano em enfrentar o tema. Segundo o jornal International Herald Tribune, o governo Berlusconi disse sobre o processo: "Este é um julgamento que nós absolutamente não deveríamos ter, e o seu resultado será o de que nosso serviço de inteligência não terá mais a cooperação da inteligência estrangeira." (ITALY..., 2007). Mesmo o governo Prodi, que inicialmente dava sinais de colaborar com a investigação, não se dispôs a solicitar a extradição dos agentes da CIA citados pelos juízes de Milão, e preferiu enviar o caso para a Corte Constitucional alegando que os magistrados de Milão haviam quebrado leis de segredo de Estado (MARINER, 2008).

A extradição dos agentes da CIAenvolvidos haviasido solicitada jáem meados de 2005 e, mesmo sem nenhum requerimento por parte do Executivo italiano, o advogado do governo dos EUA havia avisado, preventivamente, que seu país não aceitaria o pedido (JOHN, 2007). 0 ex-chefe da CIA em Milão, Robert Lady, chegou a ser representado por uma advogada nos tribunais italianos. Segundo ela, seu cliente estava decepcionado com os agentes italianos porque estes teriam "jurado" manter em segredo os detalhes que foram revelados. Além disso, ele se sentia traído porque acreditava ter feito a coisa certa para proteger os Estados Unidos e outros países $^{10} .0$ agente americano entendia que era preciso encontrar "uma solução política e não legal" para o caso, cuja resolução se daria por um acordo entre os EUA e a Itália, e não em um julgamento (MASCOLO; GEBAUER, 2007).

0 imã foi acusado também na Itália de atividades ligadas ao terrorismo - pelo que ele já vinha sendo investigado - e recebeu um mandado de prisão, o qual não se efetivou porque ele permaneceu vivendo no Egito após sua liberação. Ocorre que Abu Omar era reconhecidamente um militante contrário ao governo do então Presidente Hosni Mubarak e era proibido de sair do país. Mesmo assim, ele se dizia disposto a voltar à Itália para testemunhar sobre o caso.

Na Itália, o processo foi suspenso em junho de 2007 e retomado em maio de 2008, por ocasião de um diálogo entre o governo e a promotoria para resolver o conflito referente a documentos considerados como "segredo de Estado". Quando o caso foi reaberto, o juiz pretendia solicitar o depoimento tanto de Berlusconi quanto

\footnotetext{
10 "Ele se sente traído porque ainda acredita que fez o melhor para os EUA e para todos os outros países que combatem o Interantional Islamism" (MASCOLO; GEBAUER, 2007). A fala original da advogada não pôde ser encontrada para que se pudesse confirmar se ela realmente teria dito que a luta era contra o "Islamismo Internacional" ("Interantional Islamism"), ou se foi algum erro da reportagem.
} 
de Prodi $^{11}$, no que estava enfrentando dificuldades ${ }^{12}$. Como resultado, 21 agentes da CIA foram condenados a cinco anos de prisão e Robert Lady, o ex-chefe da agência em Milão, foi condenado a cumprir oito anos. Nenhum dos agentes americanos foi extraditado para a Itália, mas vigora um mandado de prisão da União Européia que os impossibilita de viajar legalmente pela Europa (GIMBLE, 2011).

Estes são apenas alguns exemplos que receberam maior atenção devido aos mandados de prisão emitidos. Há inúmeros outros, conhecidos ou não. Como foi dito, o destino dos indivíduos seqüestrados é também incerto, mas se sabe que o envio de prisioneiros para um ou outro local de detenção define seu futuro. Segundo um ex-oficial da CIA especialista em Oriente Médio, Robert Baer, "Há uma regra dentro da CIA que se você quiser um bom interrogatório e boas informações, deve mandar o suspeito para a Jordânia, se quiser que seja morto ou torturado até a morte, você o envia ao Egito ou Síria e nunca voltará a vêlo." (BAER apud ERTEL et al., 2005). Interessa notar ainda que, muitas vezes, os indivíduos seqüestrados eram levados à prisão de Guantánamo (KURNAZ, 2007), que se tornou símbolo do desrespeito dos Estados Unidos pelos direitos humanos, e que, segundo um dos primeiros atos do governo de Barack Obama, deveria ter sido fechada em 2010 (OBAMA, 2009), mas que continua sendo o local de detenção para suspeitos de terrorismo.

Discussões em torno dos problemas causados por essas ações do governo americano são travadas em vários países, mas não se restringem ao âmbito governamental. Muitas vezes elas surgiram por iniciativa da sociedade e se desenvolveram mais pelo esforço de organizações sociais do que por parte dos governos. É o que acontece, por exemplo, em alguns países da África ou da Ásia, regiões onde a prática é mais comum. Alguns países envolvidos dessas regiões, com consentimento dos governos locais ou não, são: Emirados Árabes Unidos, Qatar, Bahrein, Iêmen, Egito, Paquistão, Indonésia, Jordânia, Irã, Kuwait.

As controvérsias são maiores quando se trata de países europeus - o que certamente ocorre pela pretensão desses países de representarem os grandes modelos

\footnotetext{
${ }^{11}$ Essa foi uma das condições de Pollari, para que ele apresentasse o seu depoimento à justiça.

${ }^{12}$ Entre outros elementos do submundo da política, o caso envolve jornalistas trabalhando como espiões, e artimanhas do serviço secreto do governo Berlusconi para incriminar Romano Prodi - antes das eleições que elegeria o parlamento italiano que o indicaria como primeiro-ministro - de autorizar os "rendition flights" na Europa, quando este último era presidente da Comissão Européia. 0 caso ficou conhecido na Itália como "Imam Rapito". Para outras fontes, além das que foram citadas, (EFE, 2008; F00T, 2007).
} 
de direitos humanos ${ }^{13}$ e pela possibilidade de manifestação que a sociedade civil encontra ali. Além dos casos apresentados, alguns dos países do bloco europeu que, de diversos modos, estariam envolvidos nessas práticas, são: Grã-Bretanha, Grécia, Espanha, Portugal, Suécia, Lituânia, Polônia, Romênia e Macedônia (AMNESTY INTERNATIONAL, 2011) ${ }^{14}$.

Segundo o Direito Internacional, os casos das vítimas das extraordinary renditions são tratados pelo termo "desaparecimento forçado", e considerados, dentre outros documentos mais gerais ${ }^{15}$ relacionados aos direitos humanos, por uma declaração da Assembléia Geral da Organização das Nações Unidas de $1992^{16}$ sobre o tema, a "Declaração Sobre a Proteção de Todas as Pessoas Contra os Desaparecimentos Forçados" ${ }^{17}$. Mais recentemente, também por uma resolução da Assembléia Geral da ONU, chegou-se à produção de uma convenção internacional, a "Convenção Internacional para a Proteção de Todas as Pessoas Contra os Desaparecimentos Forçados"18.

13 “Na apresentação do relatório final sobre as ‘renditions', disse Sarah Lutford, deputada do Partido Liberal Democrata: 'Se as aspirações da Europa de ser uma comunidade de direitos humanos têm algum sentido, é necessário haver uma vigorosa resposta à forte evidência de que a CIA seqüestrou, aprisionou ilegalmente e transportou suspeitos de terrorismo na Europa. E governos europeus, inclusive a Inglaterra, fecharam os olhos ou colaboraram ativamente com os Estados Unidos"”. (EÇA, 2011).

${ }^{14}$ O Site "UOL Notícias" produziu um mapa, a partir do relatório da Comissão Européia, mostrando alguns países envolvidos nas extraordinary renditions (AÇÕES..., 2007; BURNS, 2008).

${ }^{15}$ Dentre os quais o mais discutido é a "Convenção contra a tortura e outros tratamentos ou penas cruéis, desumanos ou degradantes" (CAT na sigla em inglês) adotada pela Resolução 39/46 de 10 de dezembro de 1984.

${ }^{16}$ Resolução 47/133 de 18 de dezembro de 1992.

${ }^{17}$ Esta declaração, além de condenar o desaparecimento forçado em qualquer circunstância (Artigo 7: "Nenhuma circunstância, qualquer que seja, mesmo em se tratando de ameaça de guerra, estado de guerra, instabilidade política interna ou qualquer outro estado exceção, pode ser invocada para justificar os desaparecimentos forçados"), pretende garantir que a execução ou a ordem para realizar os seqüestros possam ser julgadas e punidas. Exige também que as informações das vítimas desses procedimentos possam ser obtidas prontamente (Artigo 10, parágrafo 2: "Deverá ser proporcionada informação expedita e exata sobre a detenção dessas pessoas e sobre o local ou locais onde as mesmas estão, incluindo os lugares de transferência, aos membros da sua família, ao seu advogado ou a qualquer outra pessoa que tenha interesse legitimo em conhecer essa informação, salvo se as pessoas privadas de liberdade manifestaram-se contrariamente." (Disponível no site: http://www.unhchr.ch/huridocda/huridoca.nsf/(Symbol)/A. RES.47.133.En?OpenDocument). Tradução para o português disponível em: http://www.dhnet.org. br/direitos/sip/onu/desaparec/lex71.htm).

${ }^{18}$ Criada pela resolução A/RES/61/177, de 20 de dezembro de 2006.

O ANTITERRORISMO APÓS O 11/09...

G. A.TeIXeIra JÚNIOR • 151 
Os indivíduos seqüestrados são, portanto, tratados como "desaparecidos" e, apesar de não ser possível traçar uma estimativa precisa, já em 2006 se estimava centenas de casos, pois conforme o relatório da Anistia Internacional (2006) citado, o Primeiro-Ministro egípcio à época dissera que até 2005 os EUA haviam transferido algo entre sessenta e setenta prisioneiros, apenas para seu país. Segundo estimativas posteriores do Parlamento Europeu, entre 2001 e 2007 a CIA operou, pelo menos, 1245 ghost flights, "mas todas as informações sobre esses vôos, incluindo quem eram os passageiros e o número de pessoas seqüestradas, permanecem cobertas de segredo" (GIMBLE, 2011).

\section{A legitimaÇão do POLICIAMENTO GLOBAL}

A prática de policiamento internacional por parte dos Estados Unidos, seja sob sua faceta de intervencionismo mais tradicional, seja nos moldes mais atuais, não é nem recente nem ocasional. Mesmo que determinados gestões presidenciais a utilizem com mais freqüência ou de modo mais agressivo, não se trata de uma política de governo, mas de Estado.

Embora tenham adquirido seu formato atual no governo Clinton, os seqüestros no exterior realizados sob as ordens do governo americano ganharam mais visibilidade no período Bush porque foi durante este período que elas se tornaram mais recorrentes. Além disso, assim como fez no campo da política interna, Bush tentava legitimar políticas anteriores até então realizadas clandestinamente, e, portanto, precisava trazê-las à luz (ALVES, 2011).

Em conformidade com o discurso de mudança com o qual assumiu a presidência, Obama buscou dar sinais de que modificaria os fatores mais controversos associados às extraordinary renditions, como a prática de tortura e as prisões secretas dos Estados Unidos no exterior. No início de seu mandato ele expediu uma série de decretos pelos quais determinava o fechamento das prisões da CIA no exterior e a criação de uma força-tarefa (task force) para "rever as políticas de detenção dos Estados Unidos" (CONGRESSIONAL RESEARCH SERVICE, 2009, p. 23). Não obstante, o relatório do órgão do Congresso americano sobre o tema, produzido em 2009, já assinalava que os decretos "não modificam expressamente a política de renditions dos Estados Unidos [...]” (CONGRESSIONAL RESEARCH SERVICE, 2009, p. 23). De fato, em agosto daquele mesmo ano, noticiava-se 0 seqüestro de um cidadão libanês no Afeganistão e seu deslocamento forçado - não 
sem o envolvimento de maus-tratos - para os Estados Unidos (DROGIN, 2009) ${ }^{19}$. Fora este, contudo, não há muitos relatos sobre tais práticas após a era Bush.

Apesar de o governo Obama ter diminuído o número de seqüestros realizados por seus agentes no exterior, ele continuou - e com sucesso - o esforço do seu antecessor para que os tribunais americanos não julgassem os casos relacionados a tais práticas (SAVAGE, 2010). Sobre a política de renditions, após 2009, é preciso observar o que aponta Noah Gimble (2011) ao sustentar que o governo Obama evitou ter sua imagem associada a tais práticas, porque este não queria sofrer os desgastes que elas produziram no governo Bush. Isso, porém, não significa nem que os EUA abandonaram seu papel de "polícia do mundo", e nem mesmo que se passou a adotar uma postura menos agressiva na política de antiterrorismo. Gimble argumenta que dois procedimentos foram utilizados pelo novo governo em substituição às renditions: 1) exportar as práticas para os países aliados na África e no Oriente Médio e; 2) matar os suspeitos, ao invés de prender.

No primeiro caso, as forças militares de certos países recebem o apoio das agências americanas, as quais inclusive participam dos interrogatórios dos suspeitos seqüestrados. No que se refere ao segundo tipo de procedimento, o autor menciona o lançamento de mísseis por veículos aéreos não tripulados, os chamados "drones". Ele acrescenta que "em dois anos, a administração Obama lançou mais ataques com drones do que a administração Bush ao longo de seus oito anos" e que 0 índice de civis mortos nesses ataques é estimado em até noventa por cento (GIMBLE, 2011).

Mas esse não éo único modo pelo qual o governo americano mata seus alvos individuais no exterior. Convém relembrar o ainda obscuro assassinato de Osama bin Laden no Paquistão. Certamente este ato foi executado com mais cautela porque era uma ação destinada a se tornar pública. Isto é, se o ataque gerasse "efeitos colaterais" sobre civis, a ação não poderia ser exposta como símbolo da legitimidade do policiamento internacional, como se pretendeu mostrá-la. Aliás, não apenas se pretendeu como aparentemente se conseguiu, pois as palavras de Obama ao anunciar a morte do terrorista saudita dizendo que "justiça foi feita" ressoou também no discurso do Secretário-Geral da ONU, que louvou em seguida

\footnotetext{
${ }^{19}$ Capturado por agentes do FBI em abril de 2009, Raymond Azar foi encapuzado, despido para ser fotografado e, transportado amarrado até os EUA. Segundo a mesma reportagem, a única acusação contra ele era a de "conspiração para cometer suborno". Interessa sublinhar que, diferentemente das renditions do governo Bush, Azar não foi preso com base na discricionariedade - ou arbitrariedade - de algum membro da agência do Executivo americano. Neste caso o FBI possuía "mandados de prisão assinados por um magistrado federal" (DROGIN, 2009).
}

O ANTITERRORISMO APÓS O 11/09... 
"o trabalho e o comprometimento determinado e de princípio de muitos povos no mundo que têm lutado para erradicar o terrorismo internacional." (KI-MOON, 2011) $)^{20}$.

De um modo mais geral, é a própria idéia de justiça o que as políticas antiterroristas - e não apenas dos EUA - pretendem redefinir. A conseqüência disso, obviamente, não se restringe à política externa dos Estados. Não há motivos, portanto, para os cidadãos se sentirem satisfeitos com a possibilidade de resultado dos abusos cometidos no exterior por seus governos e, ao mesmo tempo, seguros com as leis interiores. Quanto a isso, convém retomar a afirmação do sociólogo Jean-Claude Paye (2004, p. 10) segundo a qual "a luta antiterrorista tem por objetivo redesenhar a organização da sociedade". 0 autor continua: "Por meio deste processo o direito penal adquire um papel constituinte. Ele é um ato de autoridade suprema".

A afirmação é impactante, mas não parece excessiva. Paye argumenta que antes mesmo dos atos terroristas contra os EUA, em 2001, e contra a Espanha, em 2004, as democracias representativas européias já caminhavam rumo ao fortalecimento do poder do Estado frente à sociedade. Os eventos mencionados, contudo, serviram para dar legitimidade à "mutação do direito penal", permitindo que propostas antigas que eram discutidas ou implementadas longe do olhar da opinião pública fossem reveladas e justificadas retrospectivamente (PAYE, 2004, p. 8). Entende-se melhor, portanto, o significado de sua afirmação inicial. De fato, na medida em que um modo de ordenamento particular da vida social é ameaçado, qual seja, o Estado de direito, pode-se dizer que as políticas de combate ao terrorismo passam a re-estruturar a organização da sociedade. Nos Estados Unidos este ataque aos princípios do Estado de Direito é especialmente claro (ALVES, 2011). Não por outro motivo, os defensores dos direitos individuais naquele país argumentavam que o combate contra o terrorismo estava destruindo os valores constitucionais presentes na Bill of Rights.

Buscando legitimidade no discurso da segurança, a política policial avança contra a sociedade e contra o indivíduo, colocando o Estado como valor máximo. A fragilização das leis de salvaguarda individuais em âmbito interno, e o policiamento internacional realizado pelas grandes potências - e liderado pela maior delas - são anteriores às políticas estatais de combate ao terrorismo.

20 "Pessoalmente, estou muito aliviado com a notícia de que a justiça foi feita para tal mentor do terrorismo internacional. Gostaria de louvar [commend] o trabalho e o comprometimento determinado e com princípios [the determined and principled commitment] de muitas pessoas no mundo que têm lutado para erradicar o terrorismo internacional" (KI-MOON, 2011). 
Os fatos e as políticas aqui discutidos são, sem dúvida, mais uma demonstração do poder de polícia internacional de um Estado que pode ir a qualquer lugar do mundo e fazer o que bem entender, conforme suas leis ou simplesmente segundo o desígnio de seu chefe. 0 novo nisso tudo parece ser sua realização pública, sua celebração e, sobretudo, que se pretenda dar a tais práticas o nome de "justiça".

Se o apoio clandestino de um Estado a grupos políticos de outro, bem como ações de seqüestro ou políticas de assassinato conduzidas por agentes estatais podem ser consideradas como justas, o conceito de justiça inerente a tal juízo é aquele pertencente aos princípios autoritários e absolutistas, segundo os quais o justo é idêntico ao Estado, personificado na pessoa do soberano. Tal noção de justiça, enquanto busca concluir a difícil tarefa de eliminar o terrorismo derivado do extremismo religioso consolida, em contrapartida, o terrorismo de Estado. Entre Estados, grupos extremistas e indivíduos, o terrorismo é o único que parece não estar ameaçado pela nova política policial.

\section{REFERÊNCIAS}

AÇÕES ilegais da CIA na Europa. 2007. Disponível em: <http://noticias.uol.com. br/ultnot/infografico/2007/02/16/ult3224u28.jhtm> . Acesso em: 2 set. 2011.

AJCHENBAUM, Yves Marc. Les États-Unis, Gendarmes du Monde: pour le meilleur et pour le pire. Paris: Le Monde, 2003.

ALVES, T. Geraldo. Razão de estado epolítica antiterrorismo nos Estados Unidos. 2011. Tese (Doutorado em Filosofia) - Universidade Estadual de Campinas, Campinas.

AMNESTY INTERNATIONAL. Current evidence: European complicity in the CIA rendition and secret detention programmes. 2011. Disponível em: <http://www. amnesty.org/en/library/asset/EUR01/001/2011/en/77663b6e-6013-4636-9cd36b1ddb2c7181/eur010012011en.pdf>. Acesso em: 2 set. 2011.

. Rendition and secret detention: a global system of human rights violations. 2006. Disponível em: <http://www.amnesty.org/en/library/asset/ POL30/003/2006/en/db1dbfd1-d468-11dd-8743-d305bea2b2c7/pol300032006en. pdf $>$. Acesso em: 2 set. 2011.

BURNS, John F. C.I.A. used a british island to transport terrorism suspects. New York Times, New York, 22 Feb. 2008. Disponivel em: < http:/query.nytimes.com/ gst/fullpage.html?res=9A05E4D61F3FF931A15751C0A96E9C8B63 > . Acesso em: 2 set. 2011. 
CONGRESSIONAL RESEARCH SERVICE. Renditions: constraints imposed by laws on torture. 2009. Disponível em: <http://www.fas.org/sgp/crs/natsec/RL32890. pdf>. Acesso em: 2 set. 2011.

DOREL, Gérard. Atlas de l'Empire Américain. Paris: Éditions autrement, 2006.

DROGIN, Bob. Lebanese man is target of first rendition under Obama. Los Angeles Times, Los Angeles, 22 Aug. 2009. Disponível em: < http://articles.latimes. com/2009/aug/22/nation/na-rendition22 >. Acesso em: 2 set. 2011.

EÇA, Luiz. 0 seqüestro das leis. Correio da Cidadania. Disponível em: <http:// www.correiocidadania.com.br/antigo/ed537/luizeca.htm > . Acesso em: 2 set. 2011. EFE. Berlusconi e Prodi poderão depor sobre suposto seqüestro de imame pela CIA. 14 de maio de 2008. Disponível em: < http://noticias.terra.com.br/mundo/ noticias/0,,0I2886991-EI8142,00-Berlusconi+e+Prodi+devem+depor+sobre+s equestro.html>. Acesso em: 2 set. 2011.

ERTEL, Manfred et al. A guerra secreta dos EUA: no rastro da CIA. 2005. Disponível em: <http://noticias.uol.com.br/midiaglobal/derspiegel/2005/12/13/ult2682u66. jhtm>. Acesso em: 2 set. 2011.

ESCÂNDALO da CIA: 'ninguém nunca soube de nada'. Deutsche Welle, 2005. Disponível em: <http://www.dw-world.de/dw/article/0,2144,1817599,00.html>. Acesso em: 2 set. 2011.

FBI. Department of Justice. Authority of the Federal Bureau of Investigation to override international law in extraterritorial law enforcement activities. 1989. Disponível em: <http://www.fas.org/irp/agency/doj/fbi/olc_override.pdf>. Acesso em: 2 set. 2011.

FEDERATION OF AMERICAN SCIENTISTS. FAS. Note on U.S. covert action programs. Disponível em: <http://www.fas.org/sgp/advisory/state/covert.html>. Acesso em: 2 set. 2011.

F00T, John. The rendition of Abu Omar. London Review of Books, v. 29, n. 15, p. 24-25, 2007. Disponível em: <http://www.lrb.co.uk/v29/n15/foot02_html>. Acesso em: 2 set. 2011.

GIMBLE, Noah. Killing more and imprisoning less: Obama and rendition. Counter Punch, 24-26 Jun. 2011. Disponível em: <http://counterpunch.org/ gimble06242011.html>. Acesso em: 2 set. 2011.

GREENHOUSE, Linda. Supreme court refuses to hear torture appeal. New York Times, New York, 9 Oct. 2007. Disponível em: < http://www.nytimes. com/2007/10/10/washington/10scotus.html>. Acesso em: 
ITALY indicts 31 linked to CIA rendition case. International Herald Tribune, Paris, 15 Feb. 2007.

JOHN, Mark. EUA dizem que não extraditarão agentes da CIA para a Itália. Reuters, Bruxelas, 28 fev. 2007. Disponível em: <http://noticias.uol.com.br/ ultnot/reuters/2007/02/28/ult729u65219.jhtm>. Acesso em: 2 set. 2011.

KALFON, Pierre. La mise à mort de la démocratie chilienne. In: Les États-Unis, Gendarmes du Monde: pour le meilleur et pour le pire. Paris: Librio/Le Monde, 2003.

KI-M00N, Ban. Statement by the Secretary-General following the news of Osama Bin Laden's death. 2011. Disponível em: <http://www.un.org/apps/sg/ sgstats.asp?nid=5235\#> . Acesso em: 2 set. 2011.

KISSINGER, Henry. Diplomacy. New York: Simon \& Schuster, 1994.

KURNAZ, Murat. Dans l'enfer de Guantanamo. Paris: Fayard, 2007.

MARINER, Joanne. The trials of Abu Omar. Find Law, 12 Mar. 2008. Disponível em: <http://writ.news.findlaw.com/mariner/20080312.html>. Acesso em: 2 set. 2011.

MASCOLO, Georg; GEBAUER, Matthias. The CIA in the dock. DER SPIEGEL, 10 Jan. 2007. Disponível em: <http://www.spiegel.de/international/0,1518,458821,00. html>. Acesso em: 2 set. 2011.

OBAMA, Barack. Executive Order No. 13492. Review and Disposition of Individuals Detained at the Guantánamo Bay Naval Base and Closure of Detention Facilities. 2009. Disponivel em: <http://www.whitehouse.gov/the_press_office/ ClosureOfGuantanamoDetentionFacilities>. Acesso em: 2 set. 2011.

PAYE, Jean-Claude. La fin de l'État de droit: la lutte antiterroriste de l'état d'exception à la dictature. Paris: La Dispute, 2004.

SAVAGE, Charlie. Court dismisses a case asserting torture by C.I.A. New York Times, New York, 8 set. 2010. Dispónivel em: <http://www.nytimes.com/2010/09/09/ us/09secrets.html?pagewanted=all> . Acesso em: 2 set. 2011.

THE FOG of war. Direção: Errol Morris. Estados Unidos. 2003. 1 DVD (95 min), son., color.

ZAID, Mark S. Military might versus sovereign right: the kidnapping of Dr. Humberto Alvarez-Machain and the resulting fallout. Houston Journal of International Law, Houston, v. 19, n. 3, 1997. Disponível em: <http://international.vlex.com/ vid/kidnapping-alvarez-resulting-fallout-53730651 > . Acesso em: 2 set. 2011. 